1992

\title{
Numerical Solutions for Weakly Singular Hammerstein Equations and Their Superconvergence
}

\author{
Hideaki Kaneko \\ Old Dominion University, hkaneko@odu.edu \\ Richard D. Noren \\ Old Dominion University, rnoren@odu.edu
}

Yuesheng Xu

Follow this and additional works at: https://digitalcommons.odu.edu/mathstat_fac_pubs

Part of the Applied Mathematics Commons

\section{Repository Citation}

Kaneko, Hideaki; Noren, Richard D.; and Xu, Yuesheng, "Numerical Solutions for Weakly Singular Hammerstein Equations and Their Superconvergence" (1992). Mathematics \& Statistics Faculty Publications. 29.

https://digitalcommons.odu.edu/mathstat_fac_pubs/29

\section{Original Publication Citation}

Kaneko, H., Noren, R. D., \& Xu, Y. (1992). Numerical solutions for weakly singular Hammerstein equations and their superconvergence. Journal of Integral Equations and Applications, 4(3), 391-407. doi:10.1216/jiea/1181075699 
JOURNAL OF INTEGRAL EQUATIONS

AND APPLICATIONS

Volume 4, Number 3, Summer 1992

\title{
NUMERICAL SOLUTIONS FOR WEAKLY SINGULAR HAMMERSTEIN EQUATIONS AND THEIR SUPERCONVERGENCE
}

\author{
HIDEAKI KANEKO, RICHARD D. NOREN AND YUESHENG XU
}

\begin{abstract}
In the recent paper [7], it was shown that the solutions of weakly singular Hammerstein equations satisfy certain regularity properties. Using this result, the optimal convergence rate of a standard piecewise polynomial collocation method and that of the recently proposed collocationtype method of Kumar and Sloan $[\mathbf{1 0}]$ are obtained. Superconvergence of both of these methods are also presented. In the final section, we discuss briefly a standard productintegration method for weakly singular Hammerstein equations and indicate its superconvergence property.
\end{abstract}

1. Introduction. We consider the Hammerstein equation with weakly singular kernel

$$
\varphi(s)-\int_{a}^{b} g_{\alpha}(|s-t|) k(s, t) \psi(t, \varphi(t)) d t=f(s), \quad a \leq s \leq b,
$$

where

$$
g_{\alpha}(s)= \begin{cases}s^{\alpha-1} & \text { for } 0<\alpha<1 \\ \log s & \text { for } \alpha=1\end{cases}
$$

Throughout this paper, we assume that

(i) $k \in C([a, b] \times[a, b])$

(ii) $\psi \in C([a, b] \times(-\infty, \infty))$ and satisfies the Lipschitz condition $\left|\psi\left(t, y_{1}\right)-\psi\left(t, y_{2}\right)\right| \leq A\left|y_{1}-y_{2}\right|$.

In the recent paper [7], it was shown that under assumptions (i), (ii) and

(iii) $A G<1, \quad$ where $G \equiv \sup _{a \leq s \leq b} \int_{a}^{b}\left|g_{\alpha}(|s-t|) k(s, t)\right| d t$, there is a unique solution to equation (1.1).

Generalizing the argument of C. Schneider [14], regularity properties of the solution $\varphi$ were also obtained in [7]. For our present purposes, these results can be summarized as follows:

Copyright (C)1992 Rocky Mountain Mathematics Consortium 